annual report of the Lancashire and Cheshire Fauna Committee added the golden plover to an extensive list of birds recorded in inner Manchester, while in British Birds (November, vol. 26, No. 6, 1932), Mr. Eric Hardy added the hoopoe to the birds watched inside Liverpool after recording the wame species (British Birds, August, vol. 26, No. 3, 1932) in Birkenhead.

\section{Unusual Rainbow Phenomena}

A NUMBER of correspondents have added further descriptions of unusual rainbow phenomena to the account by Mr. J. L. Horton of the display of June 26 (Nature, July 8, p. 57). The month of June was unprecedented during at least the past sixty years for the number of thunderstorms, and was at the same time a generally sunny month, so that opportunities for seeing rainbows were unusually frequent. An account from J. O. Ewing, of bows seen from Brandon, Suffolk, on the evening of June 17, described three closely adjacent bows with the red farthest from the sun, of which only the outermost showed the complete range from violet to red, this being the brightest, while another bow much nearer to the sun is said to have shown colours in the reverse order. It appears possible, seeing that the effect was described from memory, that errors have been made over the colour sequences, as the bows corresponding presumably with the ordinary primary and secondary bows have the usual order of colour reversed, but even so the phenomenon was evidently very different from that described by Mr. Horton.

R. N. Jones describes something more similar that was seen from Liverpool on July 8 , except that the bow lying just outside the secondary bow was not noted, and asks whether anyone has ever seen the two bows theoretically possible in which the sun. light suffers respectively three and four internal reflections inside the raindrop, which would occur between the observer and the sun. Mr. G. H. Harker writes of having seen the phenomenon noted by Mr. Horton on several occasions, the most recent being at Clifton, Bristol, on July 10. He points out that the supernumerary bow outside the secondary is the rarer; that both depend upon the existence of a sufficient number of uniformly small droplets; and that a mixture of droplets of various sizes tends to produce overlapping systems that may give a bow of varying curvature and with a varying colour sequence in different parts of the same bow. $\mathrm{He}$ refers the reader to Airy's theory of the rainbow given more than a century ago and to the extended treatment in Chaps. xvi and xvii of Bouasse and Carrière's "Diffraction".

\section{Early Script in India}

AN interesting inscription in a rock-shelter in the Sambalpur District, Bihar and Orissa, is the subject of a note, accompanied by a series of illustrations, by Mr. K. P. Jayaswal in the Indian Antiquary for March. It appears to be in a script representing a transition from that of Mohenjo-daro to the Brahmi, and is dated tentatively at about 1500 B.c. The inscription occupies a space of $35 \mathrm{ft}$. $\times 7 \mathrm{ft}$. The letters, partly painted, partly incised, would appear all to have been painted before being cut. There is no sign of the use of an iron tool. The inscription is unquestionably writing, and Mr. Jayaswal is of the opinion that the hand responsible for the inscription was accustomed to the use of the pen. The writing appears to have reached the syllabary (alphabetical) stage. The script resembles Brahmi more closely than any other, but a number of resemblances to Mohenjodaro are noted. Notwithstanding the Brahmi cast of the inscription, it does not follow that the language is Aryan, and in view of the locality in which it has been found, it may be a pre-Dravidian Raksasa record, Raksasa being used as a generic term for the peoples dispossessed by the Aryans, now possibly represented by the Gônds.

\section{Archæological Field Work in America}

NotwithstaNDING the summary character of the reports in the annual "Explorations and Field-Work of the Smithsonian Institution", its publication is always welcome as an early source of information on recent activities in the scientific exploration of America, especially in archæology and ethnology, pending the issue of full reports. The comprehensive character of this publication which, as a rule, covers all the operations of the staff in the field, also serves to indicate the general trend of research. In the issue for 1932 (Publication 3213), for example, the problem of early man in America is attacked from several aspects. Dr. Aleš Hrdlička's archæological exploration of Kodiak Island, Alaska, and Mr. Henry B. Collins's investigations at Point Barrow, Alaska, have advanced the chronological and distributional classification of Eskimo cultures; Mr. Frank Setzler, investigating prehistoric cave-dwellers' sites in Texas, links positively for the first time the culture of the Big Bend area with the south-west; while Dr. Gerrit S. Miller, Jr. and Herbert W. Krieger have investigated the prehistoric cultures of islands in the West Indies with special reference to their early interrelations. Dr. Frank H. H. Roberts, Jr., continuing his excavations of Pueblo settlements in the south-western States, has carried a stage further the elucidation of the development of domestic and ceremonial buildings. Other investigations cover the mound-builders, the Indian tribes of eastern Canada and New York State and of California; and Miss Densmore continues her song-collecting activities among the Seminoles of Florida.

\section{Geo-electric Methods in Search for Oil}

RECENTLY geo-electric methods as applied to oilfield exploration have been regarded with some disfavour, but Mr. O. H. Gish in a paper on this subject (Bull. Amer. Assoc. Petroleum Geol., 16, No. 12, Dec. 1932, pp. 1337-1348) maintains that factors influencing this condemnation are subjective rather than objective. Many people still believe that electricity is endowed with a mystical power and thus the impostor has ample scope for his nefarious activities, while the bona fide geophysicist has perforce to qualify his statements. The impostor may forecast the number of barrels of oil obtainable from 